\title{
Carbendazim Resistance of Fusarium graminearum From Henan Wheat
}

\author{
Shengming Liu, ${ }^{\dagger}$ Liuyuan Fu, Shuan Wang, Jinpeng Chen, Jia Jiang, Zhiping Che, Yuee Tian, and Genqiang Chen \\ College of Forestry, Henan University of Science and Technology, Luoyang 471023, China
}

\begin{abstract}
Fusarium head blight, also called scab, is caused by Fusarium graminearum and is one of the most important destructive diseases of wheat. The frequency of carbendazim resistance in 1,132 isolates of $F$. graminearum recovered from fields in different regions of Henan Province in 2016, 2017, and 2018 was determined. A total of 31 F. graminearum isolates resistant to carbendazim were detected, including 30 moderately resistant isolates and one highly resistant isolate. The frequency of resistance of $F$. graminearum isolates to carbendazim was $2.7 \%$. The range of effective concentration $\left(\mathrm{EC}_{50}\right)$ values of 1,101 sensitive isolates and 30 moderately resistant isolates was 0.08 to $0.98 \mu \mathrm{g} \mathrm{ml} \mathrm{m}^{-1}$ and 2.73 to

the highly resistant isolate was $21.12 \mu \mathrm{g} \mathrm{ml}^{-1}$. Point mutation types of the carbendazim-resistant isolates were characterized by cloning the $\beta_{2^{-}}$ tubulin gene of 31 resistant isolates. Three point mutation types at amino acids F167Y, E198Q, and E198L in the $\beta_{2}$-tubulin gene of resistant isolates were identified. Among 31 resistant isolates, the frequency of point mutation types in F167Y, E198Q, and E198L of the $\beta_{2}$-tubulin gene was $71.0,25.8$, and $3.2 \%$, respectively. The data indicate that $F$. graminearum has developed resistance to carbendazim in Henan Province, and single point mutations at amino acid F167Y were the predominant type of mutation detected.
\end{abstract} $13.28 \mu \mathrm{g} \mathrm{ml}^{-1}$, respectively. The mean $\pm \mathrm{SD} \mathrm{EC}_{50}$ value was $0.55 \pm$ $0.13 \mu \mathrm{g} \mathrm{ml}^{-1}$ and $5.61 \pm 2.58 \mu \mathrm{g} \mathrm{ml}^{-1}$, respectively. The $\mathrm{EC}_{50}$ value of

Fusarium head blight (FHB), also called scab, is caused by the Fusarium graminearum species complex and is one of the most important diseases of wheat and other cereals (Bai and Shaner 1994; McMullen et al. 1997; Parry et al. 1995; Starkey et al. 2007). In addition to loss of wheat yield, FHB also causes a decline in wheat quality as a result of contamination with trichothecene mycotoxins (e.g., 3-acetyl-deoxynivalenol, 15-acetyl-deoxynivalenol, nivalenol, and zearalenone) that threaten human and animal health (Chen et al. 2007, 2008; Duan et al. 2018a; Liu et al. 2010, 2013; Pirgozliev et al. 2003; Proctor et al. 1995; Qiu et al. 2012, 2014). In China, FHB occurs in warm and humid areas, such as the Yellow River basin, the Huaihe River basin, and the Yangtze River basin (Chen et al. 2015; Hao et al. 2017; Liu et al. 2010, 2013; Qu et al. 2008). The Yellow River basin and Huaihe River basin are located in Henan Province, which is the main wheat production area, where 82 million hectares are planted to wheat annually. In Henan Province, the primary causal organism of FHB is $F$. graminearum, and the pathogen is a serious threat to wheat production in the area (Hao et al. 2017).

Because of a lack of wheat varieties with high resistance or immunity to FHB, chemical application has become the main method of controlling FHB. The benzimidazole fungicide, carbendazim, became available in the late 1960s and has become one of the most effective fungicides for controlling FHB during the period of wheat heading and flowering (Chen et al. 2007; Liu et al. 2010; Zhou and Wang 2001). The mechanism of action of benzimidazole fungicides is to inhibit the assembly of microtubules by binding to $\beta$-tubulin in pathogenic fungi and then to prevent the mycelial growth of phytopathogenic fungi (Leroux et al. 2002; Ma and Michailides 2005; Zhou et al. 2016; Zhu et al. 2018). Use of carbendazim and other benzimidazole fungicides over several years has resulted in

${ }^{\dagger}$ Corresponding author: S. Liu; liushengmingzb@163.com

Funding: This study was sponsored by the National Key R\&D Program of China (grant 2017YFD0201700), the National Natural Science Foundation of China (grant 31772204), the Natural Science Foundation of Henan Province (grant 162300410079), and the Young Teacher Funding Program of Henan Higher School (grant 2018GGJS051).

The author(s) declare no conflict of interest.

Accepted for publication 10 May 2019.

○) 2019 The American Phytopathological Society
Keywords: benzimidazole, fungicide resistance to carbendazim and other benzimidazole fungicides in several phytopathogenic fungi such as Botrytis cinerea, Monilinia fructicola, and Sclerotinia sclerotiorum (Bollen and Scholten 1971; Duan et al. 2018b; Liu et al. 2013, 2016, 2018; Ma and Michailides 2005; Ma et al. 2003; Schroeder and Provvidenti 1969; Zhu et al. 2016). In 1992, the first $F$. graminearum isolates resistant to carbendazim were detected in Zhejiang Province of China (Chen et al. 2007; Qiu et al. 2011; Yuan and Zhou 2005). Resistance of $F$. graminearum to carbendazim has been widely reported in other wheat growing areas in China (Chen et al. 2015; Yuan and Zhou 2005; Zhang et al. 2013). The mechanism of resistance to benzimidazole fungicides has been reported as a point mutation in the $\beta$-tubulin gene in Tapesia yallundae, T. acuformis, B. cinerea, $M$. fructicola, and S. sclerotiorum (Albertini et al. 1999; Liu et al. 2016, 2018; Ma and Michailides 2005; Ma et al. 2003; Zhu et al. 2016) or point mutation in the $\beta_{2}$-tubulin gene of $F$. graminearum at different amino acid sites at codons 167 , 198, and 200 (Chen et al. 2009, 2014, 2015; Duan et al. 2014; Qiu et al. 2011; Sevastos et al. 2016; Zhang et al. 2016).

However, to our knowledge, carbendazim resistance has not yet been reported in Henan Province. Control efficacy of carbendazim and other benzimidazole fungicides against $F$. graminearum has declined in Henan Province. We speculate that endemic $F$. graminearum may have developed resistance to carbendazim and other benzimidazole fungicides. Therefore, $F$. graminearum isolates were collected from Henan Province in 2016, 2017, and 2018, and their sensitivity to carbendazim was assessed by measuring mycelial growth on carbendazim-amended media. The $\beta_{2}$-tubulin gene of isolates that were resistant to carbendazim was cloned and the point mutation types associated with resistance were characterized.

\section{Materials and Methods}

Fungal isolates. A total of 1,132 F. graminearum isolates were obtained from FHB diseased wheat in different regions of Henan Province, China, in 2016, 2017, and 2018 (Table 1). Two to five wheat ears with FHB symptoms were collected from each field $(n=354)$, and the distance between fields was $>10 \mathrm{~km}$. A single symptomatic wheat grain from each head was washed twice in sterile water, then soaked in $0.1 \%$ sodium hypochlorite disinfection solution for $30 \mathrm{~s}$, washed twice in sterile water again, and finally blotted dry with sterile filter paper before it was transferred onto potato sucrose agar (PSA) medium (200 $\mathrm{g}$ of fresh potato tuber, $15 \mathrm{~g}$ of agar, and $20 \mathrm{~g}$ of sucrose per liter of distilled water) for 2 days at $25^{\circ} \mathrm{C}$ in the dark. After 2 days, 10 mycelial plugs (5-mm diameter) from each culture were transferred into $150 \mathrm{ml}$ of mung bean broth $(50 \mathrm{~g}$ of 
mung bean per liter of distilled water) and shaken $\left(120 \mathrm{rpm}, 25^{\circ} \mathrm{C}\right.$, 12-h photoperiod). Seven days later, double conventional microscope lens wiping paper (Taizhou Oak Filter Paper Factory, Taizhou, China) was used as a filter to line a glass funnel for spore collection. The lens wiping paper containing the mycelial plugs and hyphae was discarded, and the filtrate containing spores was collected and centrifuged at $10,000 \mathrm{rpm}$ and diluted with sterile water to $10^{3}$ spores $\mathrm{ml}^{-1}$. Ten microliters of the spore suspension was spread across the surface of a 9-cm PSA plate. A single spore was picked out using a dissecting microscope (XSP-8C; Shanghai CSOIF Co. Ltd., Shanghai, China) and cultured on a new PSA plate for 2 days at $25^{\circ} \mathrm{C}$ in the dark. A single mycelial tip from the single spore colony was transferred to a PSA slope, allowed to grow for 2 days $25^{\circ} \mathrm{C}$, and then stored at $4^{\circ} \mathrm{C}$.

Fungicide. Technical-grade carbendazim (MBC, 98\%) was provided by Jiangsu Rotam Chemistry Co. Ltd. (Suzhou, China). The fungicide was dissolved in $0.1 \mathrm{M}$ of hydrochloric acid to obtain a $10 \mathrm{mg} \mathrm{ml}^{-1}$ stock solution and stored at $4{ }^{\circ} \mathrm{C}$.

Resistance to carbendazim. To determine the carbendazim resistance of each of $1,132 \mathrm{~F}$. graminearum isolates, discriminatory doses of 1.4 and $100 \mu \mathrm{g} \mathrm{ml}^{-1}$ were used (Chen et al. 2015; Duan et al. 2014). Mycelial plugs (5-mm diameter) were transferred to PSA plates containing $0,1.4$, and $100 \mu \mathrm{g} \mathrm{ml}^{-1}$ of carbendazim. After 2 days at $25^{\circ} \mathrm{C}$ in the dark, growth of each of the $F$. graminearum isolates on PSA plates with and without carbendazim was observed. An isolate was considered sensitive if no growth occurred on PSA plates amended with $1.4 \mu \mathrm{g} \mathrm{ml}^{-1}$ of carbendazim. An isolate was considered moderately resistant if growth occurred on PSA plates amended with $1.4 \mu \mathrm{g} \mathrm{ml}^{-1}$ of carbendazim and not on PSA plates amended with $100 \mu \mathrm{g} \mathrm{ml}^{-1}$ of carbendazim. Growth of highly resistant isolates was observed on PSA plates amended with $100 \mu \mathrm{g} \mathrm{ml}^{-1}$ of carbendazim. Each concentration was replicated four times, and the experiment was replicated three times.

Range of effective concentrations of $F$. graminearum isolates to carbendazim. Effective concentration $\left(\mathrm{EC}_{50}\right)$ values of $F$. graminearum isolates to carbendazim were calculated based on the level of inhibition of mycelial growth. For the sensitive isolates, the carbendazim concentrations were $0,0.1,0.3,0.5,0.7,0.9$, and $1.0 \mu \mathrm{g} \mathrm{ml}^{-1}$. For the moderately resistant isolates, the carbendazim concentrations were $0,1.25,2.5,5,10$, and $25 \mu \mathrm{g} \mathrm{ml}^{-1}$. For the highly resistant isolates, the carbendazim concentrations were $0,2.5,5,10,25,50$, and $100 \mu \mathrm{g} \mathrm{ml}^{-1}$. In this study, 5-mm mycelial plugs were taken from the edge of the 2-day-old colony and transferred to PSA plates amended with the carbendazim concentrations. After incubation at $25^{\circ} \mathrm{C}$ in the dark for 3 days, the average diameter of each colony was measured with a cross-section method. The inhibitory rate of mycelial growth against $F$. graminearum isolates was calculated for each concentration according to the following formula: (diameter of the control diameter of each treatment)/(diameter of the control $-5 \mathrm{~mm}) \times$ $100 \% . \mathrm{EC}_{50}$ values were calculated based on the linear relationship between the $\log _{10}$ value of each concentration and the probability value of the inhibitory rate. Each treatment was repeated three times, and the experiment was repeated twice.

$\boldsymbol{\beta}_{\mathbf{2}}$-tubulin gene clone. To identify the point mutation types of carbendazim-resistant isolates, the $\beta_{2}$-tubulin gene of all resistant isolates and 10 randomly selected sensitive isolates was cloned. The genomic DNA of all target isolates was extracted using the cetyl

Table 1. Number of isolates of Fusarium graminearum recovered from wheat fields in Henan Province from 2016 to 2018 that were susceptible (S), moderately resistant (MR), or highly resistant (HR) to carbendazim

\begin{tabular}{|c|c|c|c|c|c|c|c|c|c|c|c|}
\hline \multirow{2}{*}{$\begin{array}{l}\text { Wheat fields } \\
\text { in cities }\end{array}$} & \multirow{2}{*}{$\begin{array}{l}\text { Wheat fields } \\
\text { sampled }(n)\end{array}$} & \multirow[b]{2}{*}{ Isolates $(n)$} & \multicolumn{3}{|c|}{2016} & \multicolumn{3}{|c|}{2017} & \multicolumn{3}{|c|}{2018} \\
\hline & & & $\mathbf{S}$ & MR & $\overline{\mathrm{HR}}$ & $\mathbf{S}$ & MR & $\overline{\text { HR }}$ & $\mathbf{S}$ & MR & $\overline{\text { HR }}$ \\
\hline Anyang & 12 & 37 & $-\mathrm{z}$ & - & - & 13 & 0 & 0 & 24 & 0 & $\overline{0}$ \\
\hline Hebi & 17 & 58 & - & - & - & - & - & - & 58 & 0 & 0 \\
\hline Jiaozuo & 7 & 26 & - & - & - & - & - & - & 26 & 0 & 0 \\
\hline Jiyuan & 8 & 29 & - & - & - & - & - & - & 29 & 0 & 0 \\
\hline Kaifeng & 30 & 101 & 23 & 0 & 0 & 27 & 1 & 0 & 50 & 0 & 0 \\
\hline Luohe & 16 & 48 & 11 & 0 & 0 & - & - & - & 35 & 1 & 1 \\
\hline Luoyang & 20 & 58 & - & - & - & 17 & 0 & 0 & 41 & 0 & 0 \\
\hline Nanyang & 32 & 112 & 30 & 1 & 0 & 22 & 0 & 0 & 59 & 0 & 0 \\
\hline Pingdingshan & 14 & 38 & 25 & 0 & 0 & - & - & - & 13 & 0 & 0 \\
\hline Puyang & 6 & 15 & - & - & - & - & - & - & 15 & 0 & 0 \\
\hline Shangqiu & 29 & 92 & - & - & - & 46 & 0 & 0 & 43 & 3 & 0 \\
\hline Xinxiang & 31 & 96 & 35 & 0 & 0 & 19 & 0 & 0 & 42 & 0 & 0 \\
\hline Xinyang & 22 & 67 & 25 & 0 & 0 & 28 & 0 & 0 & 14 & 0 & 0 \\
\hline Xuchang & 28 & 93 & 18 & 0 & 0 & 18 & 0 & 0 & 52 & 5 & 0 \\
\hline Zhengzhou & 15 & 44 & 28 & 0 & 0 & 16 & 0 & 0 & - & - & - \\
\hline Zhoukou & 37 & 121 & 8 & 0 & 0 & 62 & 0 & 0 & 44 & 7 & 0 \\
\hline Zhumadian & 30 & 97 & 32 & 0 & 0 & 34 & 12 & 0 & 19 & 0 & 0 \\
\hline Total & 354 & 1,132 & 235 & 1 & 0 & 302 & 13 & 0 & 564 & 16 & 1 \\
\hline
\end{tabular}

y Cities near the wheat fields that were sampled.

${ }^{\mathrm{z}}$ Dashes indicate that no samples were collected.

Table 2. Sensitivity indicated as $\mathrm{EC}_{50}$ values of Fusarium graminearum isolates to carbendazim in Henan Province

\begin{tabular}{|c|c|c|c|c|c|c|c|c|}
\hline \multirow[b]{2}{*}{ Year } & \multicolumn{3}{|c|}{$\mathbf{S}^{\mathbf{w}}$} & \multicolumn{3}{|c|}{ MR } & \multicolumn{2}{|c|}{ HR } \\
\hline & Isolates $(n)$ & $\mathrm{EC}_{50}$ range $^{\mathrm{x}}$ & Mean $\mathrm{EC}_{50} \mathbf{y}$ & Isolates $(n)$ & $\mathrm{EC}_{50}$ range & Mean $\mathrm{EC}_{50}$ & Isolates $(n)$ & $\mathrm{EC}_{50}$ \\
\hline 2016 & 235 & $0.34-0.97$ & $0.55 \pm 0.10 \mathrm{~A}$ & 1 & 8.84 & $8.84 \mathrm{~A}$ & 0 & $-^{\mathrm{z}}$ \\
\hline 2017 & 302 & $0.08-0.90$ & $0.47 \pm 0.13 \mathrm{~A}$ & 13 & $2.73-5.10$ & $3.85 \pm 0.71 \mathrm{C}$ & 0 & - \\
\hline 2018 & 564 & $0.32-0.98$ & $0.59 \pm 0.15 \mathrm{~A}$ & 16 & $2.73-13.28$ & $7.63 \pm 2.681 \mathrm{~A}$ & 1 & 21.12 \\
\hline Total & 1,101 & $0.08-0.98$ & $0.55 \pm 0.13 \mathrm{~A}$ & 30 & $2.73-13.28$ & $5.61 \pm 2.581 \mathrm{~B}$ & 1 & 21.12 \\
\hline
\end{tabular}

${ }^{\mathrm{w}} \mathrm{S}, \mathrm{MR}$, and HR indicate sensitive, moderately resistant, and highly resistant to carbendazim, respectively.

${ }^{x} \mathrm{EC}_{50}$ values are given in milligrams per liter.

y Mean values with the same letters within the same column are not significantly different according to Fisher's least significant difference $(P=0.01)$.

${ }^{z}$ Dashes indicate that no samples were collected. 
trimethylammonium bromide method (Liu et al. 2016; Möller et al. 1992).

The primers beta2F (5'-GATGCGTGAGATTGTAAGA-3') and beta2R (5'-TGAGGGTAGTAGTGAGGATA-3') were designed based on the complete sequence of the $\beta_{2}$-tubulin gene (NCBI Nucleotide Database reference sequence NC_026477.1; https:// www.ncbi.nlm.nih.gov/nuccore) using Primer Premier 6.0 software (Premier, Palo Alto, CA). Primers beta2F and beta2R were synthesized by Sangon Biotech (Shanghai, China). A 50- $\mu$ l PCR reaction mixture contained $25 \mathrm{ng}$ of genomic DNA, $0.25 \mu \mathrm{l}$ of Takara LA

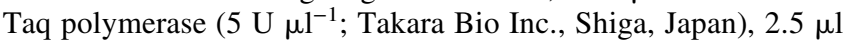
of 10× LA PCR Buffer II ( $\mathrm{Mg}^{2+}$ free; Takara Bio Inc.), $10 \mu \mathrm{l}$ of $\mathrm{MgCl}_{2}$ (25 mM; Takara Bio Inc.), $8 \mu \mathrm{l}$ of dNTP mixture $(2.5 \mathrm{mM}$ each; Takara Bio Inc.), 1.0 $\mu \mathrm{M}$ of each primer, and replenished sterile water to $50 \mu$ l. PCR reactions were performed in a TP-600 DNA Engine System (Takara Bio Inc.). The PCR procedure was performed as follows for amplification of the $\beta_{2}$-tubulin gene of $F$. graminearum: initial denaturation at $94^{\circ} \mathrm{C}$ for $5 \mathrm{~min}$, followed by 35 cycles at $94^{\circ} \mathrm{C}$ for $1 \mathrm{~min}, 57^{\circ} \mathrm{C}$ for $1 \mathrm{~min}$, and $72^{\circ} \mathrm{C}$ for $2 \mathrm{~min}$, then a final extension at $72^{\circ} \mathrm{C}$ for $10 \mathrm{~min}$, and holding at $4^{\circ} \mathrm{C}$.

All target fragments of the $\beta_{2}$-tubulin gene were separated using $2 \%$ agarose gel electrophoresis and purified with Takara MiniBEST Agarose Gel DNA Extraction Kit version 4.0. Thereafter, all fragments were cloned into the pMD18-T Simple Vector (Takara Bio Inc.) and gene sequencing was completed by Sangon Biotech. The $\beta_{2}$-tubulin gene sequences of sensitive and resistant isolates were compared, and the mutant types of resistant isolates were analyzed with BioEdit version 7.0.5.3 software (Ibis Therapeutics, Carlsbad, CA).

Statistical analysis. The data were analyzed with SPSS 14.0 (Statistical Package for the Social Sciences; SPSS Inc., Chicago, IL). Standard errors and confidence intervals for the $\mathrm{EC}_{50}$ values were determined and compared using Student's $t$ tests. Fisher's protected

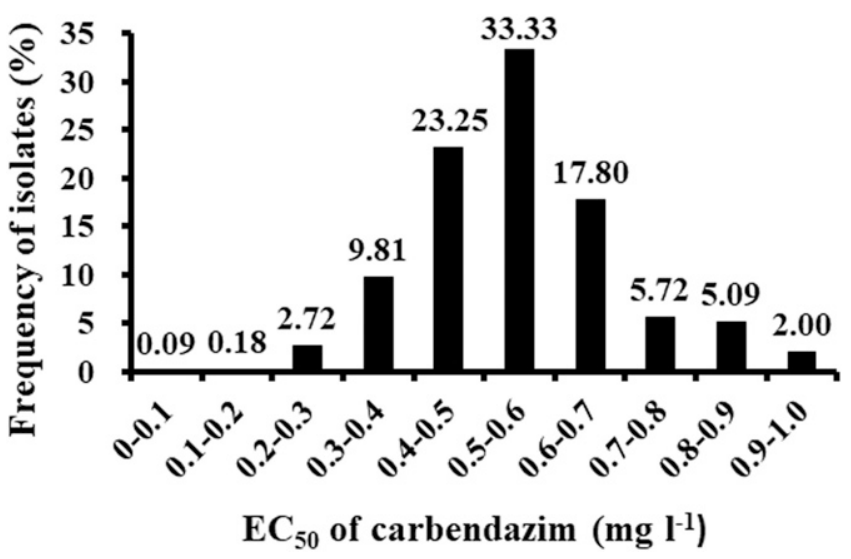

Fig. 1. Distribution of $E C_{50}$ values for sensitivity to carbendazim of 1,101 Fusarium graminearum isolates recovered from symptomatic wheat heads in Henan Province. least significant difference $(P=0.01)$ was used to test the mean $\mathrm{EC}_{50}$ values.

\section{Results}

Resistance to carbendazim. Of the 1,132 isolates of $F$. graminearum tested, 31 were characterized as resistant to carbendazim, which included 30 moderately resistant isolates and one highly resistant isolate (Table 1). Among the moderately resistant isolates, one (NY1630) was detected from Nanyang in 2016, 12 (ZMD1707, ZMD1708, ZMD1712, ZMD1713, ZMD1714, ZMD1717, ZMD1719, ZMD1740, ZMD1741, ZMD1742, ZMD1743, and ZMD1746) were detected from Zhumadian, one (KF1727) was detected from Kaifeng in 2017, and one (LH1845), three (SQ1814, SQ1837, and SQ1847), five (XC1802, XC1814, XC1819, XC1827, and XC1845), and seven (ZK1803, ZK1814, ZK1817, ZK1820, ZK1823, ZK1833, and ZK1864) were detected from Luohe, Shangqiu, Xuchang, and Zhoukou in 2018, respectively. In 2018, the only highly resistant isolate (LH1828) was detected from Luohe. The frequency of resistance to carbendazim in field isolates of $F$. graminearum from Henan Province was $2.7 \%$.

Range of $\mathrm{EC}_{50}$ values of $F$. graminearum isolates to carbendazim. The $\mathrm{EC}_{50}$ values of 1,101 sensitive isolates ranged from 0.08 to $0.98 \mu \mathrm{g} \mathrm{ml} \mathrm{m}^{-1}$, with a mean $\mathrm{EC}_{50} \pm \mathrm{SD}$ of $0.55 \pm$ $0.13 \mu \mathrm{g} \mathrm{ml}^{-1}$. $\mathrm{EC}_{50}$ values of 30 moderately resistant isolates ranged from 2.73 to $13.28 \mu \mathrm{g} \mathrm{ml}^{-1}$, whereas the mean $\mathrm{EC}_{50}$ was $5.61 \pm$ $2.58 \mu \mathrm{g} \mathrm{ml}^{-1}$ and the $\mathrm{EC}_{50}$ of the highly resistant isolate was $21.12 \mu \mathrm{g} \mathrm{ml}^{-1}$ (Table 2). The range of the frequency distribution of $\mathrm{EC}_{50}$ values for the 1,101 sensitive isolates was narrow (Fig. 1).

Sequence variation in the $\boldsymbol{\beta}_{\mathbf{2}}$-tubulin gene. Comparison of the $\beta_{2}$-tubulin gene from the 31 carbendazim-resistant isolates with the 10 sensitive isolates from which the gene was cloned and sequenced indicated a point mutation at amino acid position 167 or one of two point mutations at amino acid position 198 (Table 3). The point mutation at amino acid position 167 in 22 moderately resistant isolates resulted in a change from phenylalanine to tyrosine (TTT-TAT, PheTyr, F167Y). The single point mutation at amino acid position 198 resulted in a change from glutamic acid to glutamine (GAG-CAG, Glu-Gln, E198Q) in the other eight moderately resistant isolates. The single point mutation at amino acid position 198 in the sequence of the $\beta_{2}$-tubulin gene of the highly resistant isolate (LH1828) indicated a change from glutamic acid to leucine (GAG-CTG, Glu-Leu, E198L). Among 31 resistant isolates, the frequency of point mutation types of the $\beta_{2}$-tubulin gene at F167Y, E198Q, and E198L was 71.0, 25.8 , and $3.2 \%$, respectively (Fig. 2).

\section{Discussion}

The frequency of carbendazim resistance of $1,132 \mathrm{~F}$. graminearum isolates collected over 3 years from different regions of Henan Province along the Yellow River and Huaihe River was characterized in this study. Less than $3 \%$ of the isolates were resistant to the fungicide, which is lower than that reported in the Jiangsu and Anhui Provinces, where 15.3 and $8.2 \%$ of the isolates collected were resistant to carbendazim, respectively (Chen et al. 2015; Shao et al. 2011). The

Table 3. Point mutation types of the $\beta_{2}$-tubulin gene detected in Fusarium graminearum isolates collected from Henan Province from 2016 to 2018

\begin{tabular}{|c|c|c|c|c|c|}
\hline \multirow[b]{2}{*}{ Phenotype $^{x}$} & \multirow[b]{2}{*}{ Isolates $(n)$} & \multirow[b]{2}{*}{ Name of isolate } & \multicolumn{3}{|c|}{$\beta_{2}$-tubulin gene mutation } \\
\hline & & & $167^{y}$ & 198 & 200 \\
\hline$S$ & 10 & $\begin{array}{l}\text { NY1608, XY1624, KF1711, SQ1713, SQ1716, ZMD1710, LH1842, XC1858, } \\
\text { ZMD1818, ZK1844 }\end{array}$ & TTT F ${ }^{z}$ & GAG E & TTC F \\
\hline MR & 22 & $\begin{array}{l}\text { NY1630, KF1727, ZMD1708, ZMD1713, ZMD1714, ZMD1717, ZMD1741, } \\
\text { LH1845, SQ1814, SQ1837, SQ1847, XC1802, XC1814, XC1819, XC1827, } \\
\text { ZK1803, ZK1814, ZK1817, ZK1820, ZK1823, ZK1833, ZK1864 }\end{array}$ & TAT Y & GAG E & TTC F \\
\hline MR & 8 & $\begin{array}{l}\text { ZMD1707, ZMD1712, ZMD1719, ZMD1740, ZMD1742, ZMD1743, } \\
\text { ZMD1746, XC1845 }\end{array}$ & TTT F & $\underline{\text { CAG Q }}$ & TTC F \\
\hline HR & 1 & LH1828 & TTT F & CTG L & TTC F \\
\hline
\end{tabular}

${ }^{\mathrm{x}} \mathrm{S}, \mathrm{MR}$, and $\mathrm{HR}$ indicate sensitive, moderately resistant, and highly resistant to carbendazim, respectively.

${ }^{y}$ Amino acid position within the $\beta_{2}$-tubulin gene.

${ }^{\mathrm{z}}$ Nucleotide sequence of the codon; underlining indicates the site of the point mutation. 
reason for this phenomenon may be related to the different frequency of applications of carbendazim and other benzimidazole fungicides within a growing season in different regions of China. Since the late 1960s, growers in Jiangsu and Anhui Provinces have applied two to three applications of carbendazim and other benzimidazole fungicides per season during the period of wheat heading and flowering to manage FHB (Chen et al. 2015; Shao et al. 2011; Zhou and Wang 2001). The incidence of FHB in Henan Province is often slightly lower than that in Jiangsu and Anhui Provinces, and carbendazim and other benzimidazole fungicides are consequently applied less frequently in Henan Province. Fungicides exert selection pressure on pathogen populations; often, the more frequently a fungicide is used during a season, the greater the frequency of detecting fungicide-resistant isolates (Ma and Michailides 2005). Another reason for this phenomenon may be related to the different species of pathogens that cause FHB. FHB is mainly caused by $F$. graminearum in Henan Province and by F. asiaticum in Jiangsu and Anhui Provinces (Chen et al. 2015; Hao et al. 2017; Qu et al. 2008). Of the 31 carbendazim-resistant isolates of $F$. graminearum recovered, only one was highly resistant and able to grow on medium amended with $100 \mu \mathrm{g} \mathrm{ml}^{-1}$ of carbendazim. The resistant phenotype of the $F$. graminearum population to carbendazim in Henan Province was predominantly moderately resistant (30 of 31 resistant isolates). These data are consistent with reports on Jiangsu and Anhui Provinces where resistance to carbendazim was also detected in the population of $F$. asiaticum and $>90 \%$ of the resistant isolates were moderately resistant (Chen et al. 2015; Duan et al. 2014).

The mean $\mathrm{EC}_{50}$ value of carbendazim inhibiting the mycelial growth of 100 wild-type isolates of $F$. graminearum, which were collected from wheat fields in Jiangsu, Zhejiang, and Hubei Provinces in 1999 , was $0.57 \pm 0.01 \mu \mathrm{g} \mathrm{ml}^{-1}$ (Zhou and Wang 2001). The mean $\mathrm{EC}_{50}$ values of our isolates were not different. All of our $F$. graminearum isolates were collected from fields of wheat to which carbendazim and other benzimidazole fungicides (e.g., benomyl and thiophanate-methyl) had been applied once or twice each season. To mitigate FHB, carbendazim and other benzimidazole fungicides are applied during the period of wheat heading and flowering. In Henan Province, this application typically occurs once per season and occasionally twice when conditions are very favorable for FHB development. The sensitive isolates in our study had a narrow range of frequency distribution of $\mathrm{EC}_{50}$ values, which indicated that carbendazim still had high activity to the majority of $F$. graminearum isolates (>97\%) in Henan Province, and thus these data could be used for monitoring susceptibility to carbendazim and other benzimidazole fungicides in the $F$. graminearum population of this area.

Previous studies identified point mutations that occur within the $\beta_{2}$-tubulin gene in $F$. graminearum and $F$. asiaticum at codons $167(\mathrm{TTT} \rightarrow \mathrm{TAT}, \mathrm{F} 167 \mathrm{Y}), 198(\mathrm{GAG} \rightarrow \mathrm{CAG}, \mathrm{E} 198 \mathrm{Q} ; \mathrm{GAG} \rightarrow \mathrm{CTG}$,

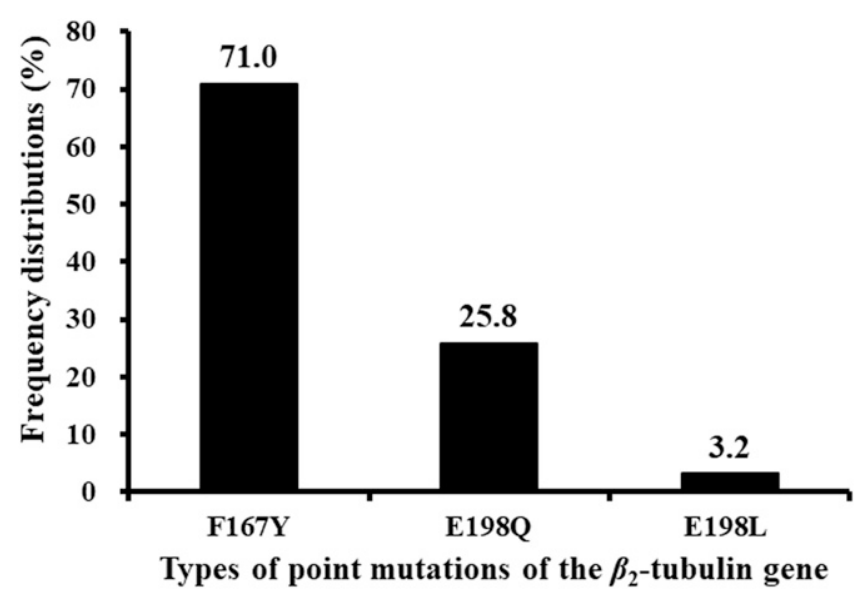

Fig. 2. Frequency of point mutation types in the $\beta_{2}$-tubulin gene of 31 Fusarium graminearum isolates that were recovered from symptomatic wheat heads in Henan Province and tested resistant to carbendazim.
$\mathrm{E} 198 \mathrm{~L} ; \mathrm{GAG} \rightarrow \mathrm{AAG}, \mathrm{E} 198 \mathrm{~K})$, and $200(\mathrm{TTC} \rightarrow \mathrm{TAC}, \mathrm{F} 200 \mathrm{Y})$ as the mechanism of resistance to benzimidazole fungicides (Chen et al. 2009, 2014, 2015; Duan et al. 2014; Qiu et al. 2011; Sevastos et al. 2016; Zhang et al. 2016). The point mutation of amino acids at different sites or different types of mutations within an amino acid at the same site can lead to different levels of resistance of $F$. graminearum to carbendazim (Chen et al. 2009; Duan et al. 2014). The point mutation types at codon F167Y, E198Q, or F200Y of the $\beta_{2^{-}}$ tubulin gene can result in moderate resistance to carbendazim, whereas E198L or E198K of the $\beta_{2}$-tubulin gene can result in high resistance to carbendazim in $F$. graminearum and $F$. asiaticum (Chen et al. 2009, 2015). Among carbendazim-resistant isolates in the field, the point mutation type in F167Y is the main type and has been confirmed in Jiangsu and Anhui Provinces by previous studies (Chen et al. 2009, 2015; Duan et al. 2014). In this study, we identified three of the reported point mutations at codons F167Y, E198Q, and E198L, of which F167Y was the most frequent. The single point mutation type at amino acid F167Y was the main type of $F$. graminearum in Henan Province, and this result is consistent with reports from Jiangsu and Anhui Provinces where the F167Y mutation was detected in $>90 \%$ of the resistant isolates of $F$. asiaticum (Chen et al. 2009, 2015; Duan et al. 2014). These data suggest the predominant single point mutation type is similar between $F$. graminearum and $F$. asiaticum.

In conclusion, FHB caused by $F$. graminearum is one of the most important destructive diseases of wheat in Henan Province of China. Fungicide spray application remains the most important way of controlling FHB during the period of heading and flowering. Detection of resistance within the $F$. graminearum population to benzimidazole fungicides is a concern for wheat production in Henan Province. Our data are important for monitoring carbendazim resistance in $\mathrm{F}$. graminearum in Henan Province and providing disease management recommendations for local wheat growers. To delay the more frequent occurrence of fungicide resistance, benzimidazole fungicides should be mixed or rotated with fungicides having different mechanisms or belonging to different FRAC Fungicide Resistance Action Committee groups. In Henan Province, products containing single fungicide tebuconazole, epoxiconazole and phenamacril, and fungicide mixes such as carbendazim plus tebuconazole, carbendazim plus epoxiconazole, thiophanate-methyl plus tebuconazole, tebuconazole plus prochloraz, trifloxystrobin plus tebuconazole, and phenamacril plus tebuconazole have been registered to control FHB (Chen et al. 2008, 2011, 2015; http://www.chinapesticide.org.cn/). The fungicides pydiflumetofen, metconazole, and metconazole plus phenamacril have all been more effective at reducing FHB than benzimidazole fungicides (Duan et al. 2019; Hou et al. 2017).

\section{Literature Cited}

Albertini, C., Gredt, M., and Leroux, P. 1999. Mutations of the $\beta$-tubulin gene associated with different phenotypes of benzimidazole resistance in the cereal eyespot fungi Tapesia yallundae and Tapesia acuformis. Pestic. Biochem. Physiol. 64:17-31.

Bai, G., and Shaner, G. 1994. Scab of wheat: Prospects for control. Plant Dis. 78: 760-766.

Bollen, G. J., and Scholten, G. 1971. Acquired resistance to benomyl and some other systemic fungicides in a strain of Botrytis cinerea in cyclamen. Neth. J. Plant Pathol. 77:83-90.

Chen, C. J., Wang, J. X., Luo, Q. Q., Yuan, S. K., and Zhou, M. G. 2007. Characterization and fitness of carbendazim-resistant strains of Fusarium graminearum (wheat scab). Pest Manag. Sci. 63:1201-1207.

Chen, C. J., Yu, J. J., Bi, C. W., Zhang, Y. N., Xu, J. Q., Wang, J. X., and Zhou, M. G. 2009. Mutations in a $\beta$-tubulin confer resistance of Gibberella zeae to benzimidazole fungicides. Phytopathology 99:1403-1411.

Chen, Y., Li, H. K., Chen, C. J., and Zhou, M. G. 2008. Sensitivity of Fusarium graminearum to fungicide JS399-19: In vitro determination of baseline sensitivity and the risk of developing fungicide resistance. Phytoparasitica 36:326-337.

Chen, Y., Wang, W. X., Zhang, A. F., and Gu, C. Y. 2011. Activity of the fungicide JS399-19 against Fusarium head blight of wheat and the risk of resistance. J. Integr. Agric. 10:1906-1913.

Chen, Y., Yang, X., Gu, C. Y., Zhang, A. F., Gao, T. C., and Zhou, M. G. 2015. Genotypes and phenotypic characterization of field Fusarium asiaticum isolates resistant to carbendazim in Anhui Province of China. Plant Dis. 99:342-346. 
Chen, Z. H., Gao, T., Liang, S. P., Liu, K. X., Zhou, M. G., and Chen, C. J. 2014. Molecular mechanism of resistance of Fusarium fujikuroi to benzimidazole fungicides. FEMS Microbiol. Lett. 357:77-84.

Duan, Y. B., Tao, X., Zhao, H. H., Xiao, X. M., Li, M. X., Wang, J. X., and Zhou, M. G. 2019. Activity of demethylation inhibitor fungicide metconazole on Chinese Fusarium graminearum species complex and its application in carbendazim-resistance management of Fusarium head blight in wheat. Plant Dis. 103:929-937.

Duan, Y. B., Xiao, X. M., Li, T., Chen, W. W., Wang, J. X., Fraaije, B. A., and Zhou, M. G. 2018a. Impact of epoxiconazole on Fusarium head blight control, grain yield and deoxynivalenol accumulation in wheat. Pestic. Biochem. Physiol. 152:138-147.

Duan, Y. B., Yang, Y., Wang, J. X., Chen, C. J., Steinberg, G., Fraaije, B. A., and Zhou, M. G. 2018b. Simultaneous detection of multiple benzimidazole-resistant beta-tubulin variants of Botrytis cinerea using loop-mediated isothermal amplification. Plant Dis. 102:2016-2024.

Duan, Y. B., Zhang, X. K., Ge, C. Y., Yong, W., Cao, J. H., Jia, X. J., Wang, J. X., and Zhou, M. G. 2014. Development and application of loop-mediated isothermal amplification for detection of the F167Y mutation of carbendazim-resistant isolates in Fusarium graminearum. Sci. Rep. 4:7094.

Hao, J. J., Xie, S. N., Sun, J., Yang, G. Q., Liu, J. Z., Xu, F., Ru, Y. Y., and Song, Y. L. 2017. Analysis of Fusarium graminearum species complex from wheatmaize rotation regions in Henan (China). Plant Dis. 101:720-725.

Hou, Y. P., Mao, X. W., Wang, J. X., Zhan, S. W., and Zhou, M. G. 2017. Sensitivity of Fusarium asiaticum to a novel succinate dehydrogenase inhibitor fungicide pydiflumetofen. Crop Prot. 96:237-244.

Leroux, P., Fritz, R., Debieu, D., and Albertini, C. 2002. Mechanisms of resistance to fungicides in field strains of Botrytis cinerea. Pest Manag. Sci. 58:876-888.

Liu, S. M., Che, Z. P., and Chen, G. Q. 2016. Multiple-fungicide resistance to carbendazim, diethofencarb, procymidone, and pyrimethanil in field isolates of Botrytis cinerea from tomato in Henan Province, China. Crop Prot. 84:56-61.

Liu, S. M., Chen, Y., Yu, J. J., Chen, C. J., Wang, J. X., and Zhou, M. G. 2010. Transfer of the $\beta$-tubulin gene of Botrytis cinerea with resistance to carbendazim into Fusarium graminearum. Pest Manag. Sci. 66:482-489.

Liu, S. M., Duan, Y. B., Ge, C. Y., Chen, C. J., and Zhou, M. G. 2013. Functional analysis of the $\beta 2$-tubulin gene of Fusarium graminearum and the $\beta$-tubulin gene of Botrytis cinerea by homologous replacement. Pest Manag. Sci. 69:582-588.

Liu, S. M., Zhang, Y., Jiang, J., Che, Z. P., Tian, Y. E., and Chen, G. Q. 2018. Carbendazim resistance and dimethachlone sensitivity of field isolates of Sclerotinia sclerotiorum from oilseed rape in Henan Province, China. J. Phytopathol. 166:701-708.

Ma, Z. H., and Michailides, T. J. 2005. Advances in understanding molecular mechanisms of fungicide resistance and molecular detection of resistant genotypes in phytopathogenic fungi. Crop Prot. 24:853-863.

Ma, Z. H., Yoshimura, M., and Michailides, T. J. 2003. Identification and characterization of benzimidazole resistance in Monilinia fructicola from stone fruit orchards in California. Appl. Environ. Microbiol. 69:7145-7152.

McMullen, M. P., Jones, R., and Gallenberg, D. 1997. Scab of wheat and barley: A re-emerging disease of devastating impact. Plant Dis. 81:1340-1348.

Möller, E. M., Bahnweg, G., Sandermann, H., and Geiger, H. H. 1992. A simple and efficient protocol for isolation of high molecular weight DNA from filamentous fungi, fruit bodies, and infected plant tissues. Nucleic Acids Res. 20:6115-6116.

Parry, D. W., Jenkinson, P. J., and Mcleod, L. 1995. Fusarium ear blight (Scab) in small grain cereals_-a review. Plant Pathol. 44:207-238.
Pirgozliev, S. R., Edwards, S. G., Hare, M. C., and Jenkinson, P. 2003. Strategies for the control of Fusarium head blight in cereals. Eur. J. Plant Pathol. 109: 731-742.

Proctor, R. H., Hohn, T. M., and McCormick, S. P. 1995. Reduced virulence of Gibberella zeae caused by disruption of trichothecene toxin biosynthesis gene. Mol. Plant-Microbe Interact. 8:593-601.

Qiu, J. B., Huang, T. T., Xu, J. Q., Bi, C. W., Chen, C. J., and Zhou, M. G. 2012 $\beta$-tubulins in Gibberella zeae: Their characterization and contribution to carbendazim resistance. Pest Manag. Sci. 68:1191-1198.

Qiu, J. B., Xu, J. H., and Shi, J. R. 2014. Molecular characterization of the Fusarium graminearum species complex in eastern China. Eur. J. Plan Pathol. 139:811-823

Qiu, J. B., Xu, J. Q., Yu, J. J., Bi, C. W., and Zhou, M. G. 2011. Localisation of the benzimidazole fungicide binding site of Gibberella zeae $\beta_{2}$-tubulin studied by site-directed mutagenesis. Pest Manag. Sci. 67:191-198.

Qu, B., Li, H. P., Zhang, J. B., Xu, Y. B., Huang, T., Wu, A. B., Zhao, C. S., Carter J., Nicholson, P., and Liao, Y. C. 2008. Geographic distribution and genetic diversity of Fusarium graminearum and $F$. asiaticum on wheat spikes throughout China. Plant Pathol. 57:15-24.

Schroeder, W. T., and Provvidenti, R. 1969. Resistance to benomyl in powdery mildew of cucurbits. Plant Dis. Rep. 53:271-275.

Sevastos, A., Markoglou, A., Labrou, N. E., Flouri, F., and Malandrakis, A. 2016. Molecular characterization, fitness and mycotoxin production of Fusarium graminearum laboratory strains resistant to benzimidazoles. Pestic. Biochem. Physiol. 128:1-9.

Shao, Z. R., Zhou, M. G., Qiu, J. B., Yang, R. M., Diao, Y. M., and Zhang, S. 2011 The occurrence, resistance to carbendazim of wheat scab and its control measures in Jiangsu Province in 2010. Agrochemicals 50:385-389.

Starkey, D. E., Ward, T. J., Aoki, T., Gale, L. R., Kistler, H. C., Geiser, D. M. Suga, H., Tóth, B., Varga, J., and O’Donnell, K. 2007. Global molecular surveillance reveals novel Fusarium head blight species and trichothecene toxin diversity. Fungal Genet. Biol. 44:1191-1204.

Yuan, S. K., and Zhou, M. G. 2005. A major gene for resistance to carbendazim, in field isolates of Gibberella zeae. Can. J. Plant Pathol. 27:58-63.

Zhang, H., Brankovics, B., Lee, T. A. J. V. D., Waalwijk, C., Diepeningen, A. A D. V., Xu, J., Xu, J. S., Chen, W. Q., and Feng, J. 2016. A single-nucleotidepolymorphism-based genotyping assay for simultaneous detection of differen carbendazim-resistant genotypes in the Fusarium graminearum species complex. PeerJ 4:e2609.

Zhang, L. G., Jia, X. J., Chen, C. J., and Zhou, M. G. 2013. Characterization of carbendazim sensitivity and trichothecene chemotypes of Fusarium graminearum in Jiangsu Province of China. Physiol. Mol. Plant Pathol. 84: 53-60.

Zhou, M. G., and Wang, J. X. 2001. Study on sensitivity baseline of Fusarium graminearum to carbendazim and biological characters of MBC-resistant strains. Acta Phytopathol. Sin. 31:365-370.

Zhou, Y. J., Zhu, Y. Y., Li, Y. J., Duan, Y. B., Zhang, R. S., and Zhou, M. G. 2016. $\beta 1$ tubulin rather than $\beta 2$ tubulin is the preferred binding target for carbendazim in Fusarium graminearum. Phytopathology 106:978-985.

Zhu, Y. Y., Liang, X. Y., Li, Y. J., Duan, Y. B., and Zhou, M. G. 2018. F240 of $\beta 2-$ tubulin explains why Fusarium graminearum is less sensitive to carbendazim than Botrytis cinerea. Phytopathology 108:352-361.

Zhu, Z. Q., Zhou, F., Li, J. L., Zhu, F. X., and Ma, H. J. 2016. Carbendazim resistance in field isolates of Sclerotinia sclerotiorum in China and its management. Crop Prot. 81:115-121. 